\title{
The vulnerability sourcebook and climate impact chains - a standardised framework for a climate vulnerability and risk assessment
}

Vulnerability sourcebook and climate impact

\author{
Marc Zebisch, Stefan Schneiderbauer, Kerstin Fritzsche, \\ Philip Bubeck, Stefan Kienberger, Walter Kahlenborn, \\ Susanne Schwan and Till Below \\ (Author affiliations can be found at the end of the article)
}

\begin{abstract}
Purpose - This paper aims to present the "Vulnerability Sourcebook" methodology, a standardised framework for the assessment of climate vulnerability and risk in the context of adaptation planning. The Vulnerability Sourcebook has been developed for the Deutsche Gesellschaft für Internationale Zusammenarbeit (GIZ) and has been applied in more than twenty countries worldwide.

Design/methodology/approach - It is based on a participative development of so-called climate impact chains, which are an analytical concept to better understand, systemise and prioritise the climate factors as well as environmental and socio-economic factors that drive climate related threats, vulnerabilities and risks in a specific system. Impact chains serve as the backbone for an operational climate vulnerability assessment with indicators based on quantitative approaches (data, models) combined with expert assessments. In this paper, the authors present the concept and applications of the original Vulnerability Sourcebook, published in 2015, which was based on the IPCC AR4 concept of climate vulnerability. In Section 6 of this paper, the authors report how this concept has been adapted to the current IPCC AR5 concept of climate risks.

Findings - The application of the Sourcebook is demonstrated in three case studies in Bolivia, Pakistan and Burundi. The results indicate that particularly the participative development of impact chains helped with generating a common picture on climate vulnerabilities and commitment for adaptation planning within a region. The mixed methods approach (considering quantitative and qualitative information) allows for a flexible application in different contexts. Challenges are mainly the availability of climate (change) and socio-economic data, as well as the transparency of value-based decisions in the process.

Originality/value - The Vulnerability Sourcebook offers a standardised framework for the assessment of climate vulnerability and risk in the context of adaptation planning.
\end{abstract}

Keywords Climate change, Adaptation, Vulnerability assessment, Indicators, Risk assessment, Impact chains

Paper type Research paper

(C) Marc Zebisch, Stefan Schneiderbauer, Kerstin Fritzsche, Philip Bubeck, Stefan Kienberger, Walter Kahlenborn, Susanne Schwan and Till Below. Published by Emerald Publishing Limited. This article is published under the Creative Commons Attribution (CC BY 4.0) licence. Anyone may reproduce, distribute, translate and create derivative works of this article (for both commercial and non-commercial purposes), subject to full attribution to the original publication and authors. The full terms of this licence may be seen at http://creativecommons.org/licences/by/4.0/legalcode

The development of the Vulnerability Sourcebook and the case studies have been financed and commissioned by the Deutsche Gesellschaft für internationale Zusammenarbeit (GIZ). In addition we would like to thank colleagues from GIZ Bolivia, Burundi and Pakistan for their collaboration and support with the case studies.

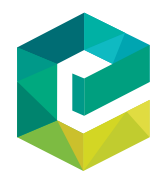

Received 17 July 2019

Revised 8 April 2020

29 July 2020

9 October 2020

27 October 2020

Accepted 28 October 2020 
IJCCSM

13,1

\section{Background - Why a generic approach for a vulnerability assessment?}

With the increasingly adverse effects of climate change, especially in developing and least developed countries (LDC) (Field et al., 2014), adaptation to climate change stands high on the agenda of national and international programs. Already in 2010, the United Nation Framework Convention on Climate Change (UNFCCC) initiated the National Adaptation Plan processes (NAP) (UNFCCC, 2013), which aims at reducing the vulnerability of respective countries and most vulnerable groups by addressing medium- and long-term adaptation needs. In the context of NAPs, the LDC Expert group has emphasised the need for a vulnerability and risk assessment approach to support adaptation planning, particularly at the national, subnational and sector level (Least Developed Countries Expert Group, 2012). Furthermore, with larger funds for adaptation measures, for instance through the Green Climate Fund (GCF, 2011) the need for indicators to monitor and evaluate the success of adaptation measures in reducing risks and vulnerabilities is becoming increasingly prominent (Lamhauge et al., 2012). Various generic guidelines and frameworks exist (CARE, 2009; UNDP, 2010; PROVIA, 2013). However, most of them lack instructions for an operational vulnerability and risk assessment that allows for comparison in time and/ or space, which is a core pre-requisite for monitoring and evaluation purposes. Responding to this demand, the Deutsche Gesellschaft für Internationale Zusammenarbeit (GIZ) commissioned the "Vulnerability Sourcebook" (Fritzsche et al., 2015), a standardised methodological framework for climate change vulnerability assessments. This framework is applicable to vulnerability and risk assessments from national to local scale. It follows the full planning cycle of the adaptation process, from identification of the adaptation demand and selection of measures, to the monitoring and evaluation of the success of adaptation interventions in lowering vulnerability.

According to GIZ's experience, (national) climate adaption planning is often subject to a number of barriers (Table 1) such as limited availability of climate change information, lack of awareness of the need for climate resilient development, lack of capacity among key stakeholders and institutions, as well as lack of agreed priorities for climate resilient development (GIZ, 2014; Klein et al., 2014; OECD, 2015). The authors argue that the structured and participatory approach of the sourcebook can help to overcome some of these barriers by capacity building of and co-development with key stakeholders and institutions from the beginning and by focussing not only on climate (change) as a driver but also on non-climatic drivers of climate vulnerability.

\section{Conceptual framework: climate change impact, vulnerability, adaptation}

The Sourcebook's approach is based on the commonly applied concept of climate change vulnerability as proposed by the Fourth Assessment Report (AR4) of the Intergovernmental Panel on Climate Change (IPCC). Meanwhile, the current IPCC-AR5 WII report (Field et al., 2014) introduced a new concept of "climate risk", which is closer to the disaster risk community than the AR4 concept. It differs in terminology, but the general idea is the same: To understand the underlying root-causes of potential negative climate impacts, including climatic, natural, physical and socio-economic factors. The authors have already developed a set of instructions of how the Sourcebook can be applied with the IPCC AR5 climate risk approach (Zebisch et al., 2017) and many of the most recent Sourcebook applications are already following this new AR5 climate risk approach. However, as the original Vulnerability Sourcebook and the lessons learnt from its first applications have not so far been published, the authors refer to the AR4 concept throughout this paper. A short summary of how the impact chain concept can be applied with the AR5 risk concept is given in Section 6. 
According to the IPCC AR4, vulnerability is:

[...] the degree to which a system is susceptible to, and unable to cope with, adverse effects of climate change, including climate variability and extremes. Vulnerability is a function of the character, magnitude, and rate of climate change and variation to which a system is exposed, its sensitivity, and its adaptive capacity (Parry et al., 2007).

Vulnerability sourcebook and climate impact

Various concepts exist that particularly differ on what the term "vulnerability" stands for, such as the disaster risk concept (United Nations Department of Humanitarian Affairs, 1992; Crichton, 1999), where vulnerability is only one aspect of the system, which determines the "harm" expressed as a "risk". Often concepts are intermingled, which contributes to considerable confusion regarding the conceptualizations of vulnerability to climate change (Füssel, 2010).

For an in-depth discussion of terms and concepts of climate change and vulnerability in the AR4 logic see: Brooks, 2003; Dessai and Hulme, 2004; Adger, 2006; Füssel and Klein, 2006; Metzger and Schröter, 2006; Thomalla et al., 2006; Füssel, 2007; O'Brien et al., 2007; Hinkel, 2008, 2011; Wolf et al., 2013. For a discussion on the IPCC AR5 concept of climate risk see Section 6 as well as Oppenheimer et al., 2014; Zebisch et al., 2017; Adger et al., 2018.

In accordance with the IPCC-AR4 definition, the Sourcebook distinguishes between three key components that determine vulnerability to climate change: exposure, sensitivity, and adaptive capacity. Furthermore, in-line with Schröter et al. (2005); Metzger and Schröter (2006) and others, the component of "potential Impact" as an intermediate component was added.

Exposure (E) defines the character, magnitude, and rate of change and variation in the climate to which a system is exposed. Typically, exposure includes factors such as temperature, precipitation, climatic water balance, as well as extreme events such as heavy rainfall or meteorological droughts.

Sensitivity (S) determines the degree to which a system is adversely (or beneficially) affected by a given climate (change) exposure. In the author's concept, sensitivity may be determined by (a) natural/physical factors of a system such as ecosystem types, land cover, slope, water holding capacity and erodibility of soils, (b) natural/physical factors related to human land management activities and infrastructure, such as the existence and quality of dikes, terraces, irrigation systems, houses, roads, electrical grids, (c) societal factors, such as population density or age structure.

Potential impacts (PI) are the combined effect of exposure and sensitivity without additional adaptation activities. For instance, torrential rain events (exposure) in combination with steep slopes and sandy soils (sensitivity) will result in erosion, loss of land and, consequently, loss of yield (potential impact). Climate change impacts can be more direct, such as erosion, or indirect, such as loss of income due to a reduction in agricultural yields.

Adaptive capacity (AC) describes the ability of a society, a social group or individuals to actively adapt to climate change, climate variability and climate extremes by moderating potential damages, taking advantages of opportunities, or coping with the consequences. Compared to the IPCC AR4 definition (Parry et al., 2007), the (autonomous) adaption of ecosystems is explicitly excluded, which, in the author's understanding, is part of sensitivity. Factors which determine adaptive capacity include economy, governance, knowledge, and available adaptation options (ecosystem-based as well as technical), (Adger et al., 2004; Preston et al., 2009).

Adaptation measures and their effect have not yet been conceptually integrated into the vulnerability concept. Adaption is the process of adjustment to actual or expected climate 
IJCCSM

13,1

38

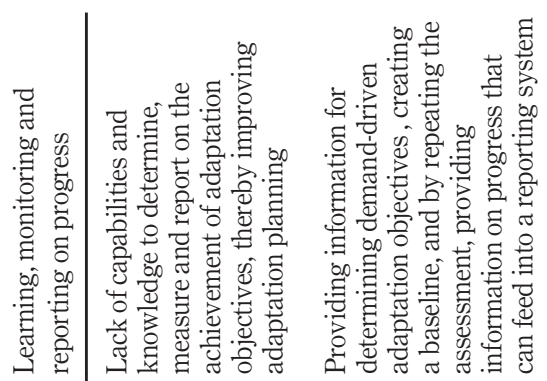

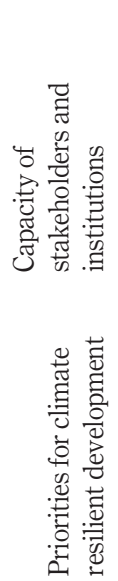

范范兽
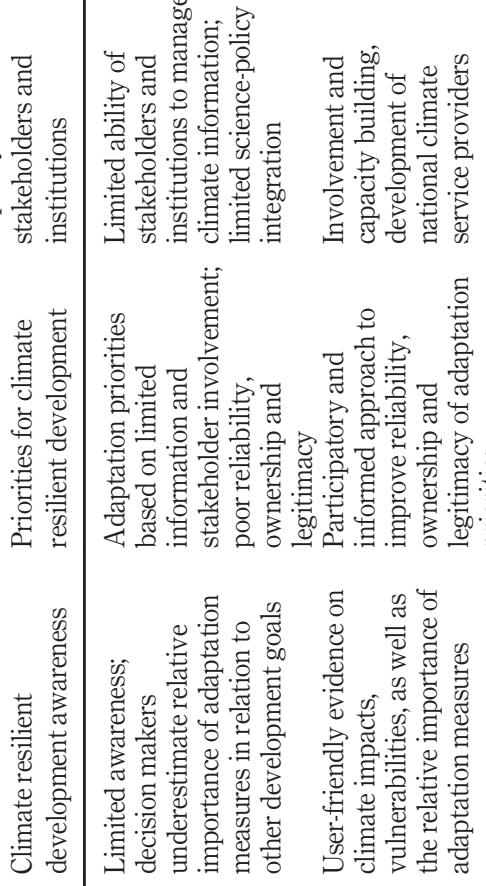

Table 1.

Typical barriers in (national) adaptation planing and potential contribution of the vulnerability sourcebook to overcome them. Own summary

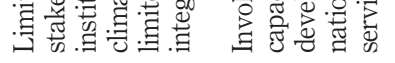

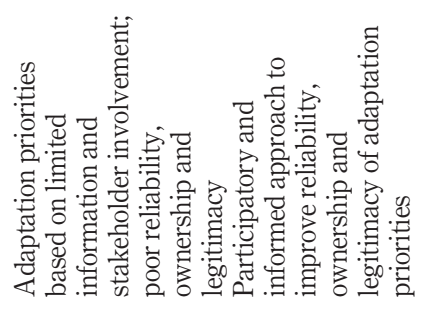

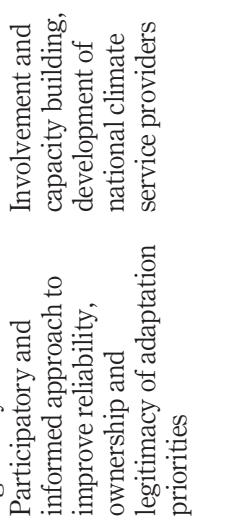

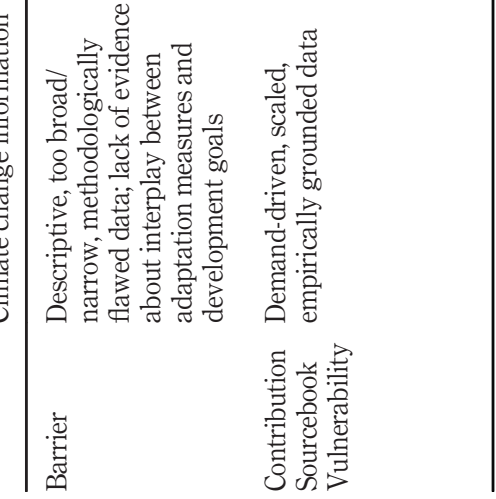


and its effects (Field et al., 2014). Adaptation can cover a wide range of approaches, such as ecosystem-based approaches (natural retention areas for flood protection), technical measure (e.g. dikes), information-based measures (training on climate change adaptation), economic measures (diversification of production), or governance and participation measures (e.g. round tables). For ecosystem based approaches see the latest publication on climate risk assessment in the context of Ecosystem based Adaptation (Hagenlocher et al., 2018)

The authors propose to integrate adaptation into the vulnerability concept by assuming that adaptation lowers vulnerability by lowering sensitivity and/or increasing adaptive capacity (see Figure 1).

\subsection{Can vulnerability be measured? Or: how to assess vulnerability?}

The authors fully support Hinkel's statement that:

vulnerability cannot be measured because vulnerability does not denote an observable phenomenon. Since vulnerability is a theoretical concept, it is more accurate to speak about making the concept operational instead of measuring it (Hinkel, 2011).

As a result, the authors prefer to use the term assessing instead of measuring vulnerability and propose a system of how to operationalise this assessment. The authors thus take into account that the concept of vulnerability of a given system is based very much on normative values and questions such as: what do we want to protect? How important or relevant is a potential impact for the system's function? Due to the value-based character of vulnerability, a vulnerability assessment can never be objective and independent of the values of the "owner" of this system, which may even differ between different groups of stakeholders.

A common and valid approach to take into account the qualitative and value-based nature of vulnerability, particularly at the local scale, is to base the assessment on a bottom-up and participatory appraisal, using mainly qualitative information and narratives (CARE, 2009). However, this is barely possible for larger scales (trans-national to global). For these, a set of top-down approaches for data driven vulnerability assessments exists, which are based on standardised composite indicators, mainly for climate change, partly complemented by socio-economic indicators (Baettig et al., 2007; Piontek et al., 2014; Maplecroft, 2015). Here, value-based decisions are usually implicitly

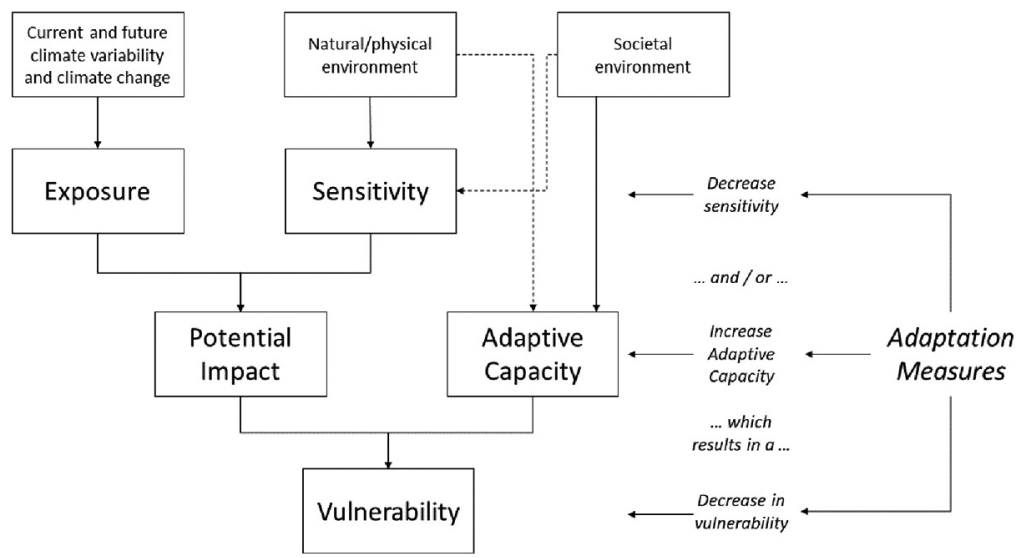

\section{Piontek et al., 2014; Maplecroft, 2015). Here, value-based decisions are usually implicitly}

Vulnerability sourcebook and climate impact

39 
IJCCSM

13,1

made through the selection of indicators. For a discussion on global indicators for hotspot mapping see de Sherbinin (2014).

Despite this restriction for measuring vulnerability, the demand of decision-makers and funding agencies for comparing the vulnerability across spatial regions, even at the subnational scale (e.g. municipalities), or monitoring and evaluating vulnerability through time (e.g. before and after an adaptation measure) requires an assessment scheme, which is not only based on narratives but reproducible and transparent. This calls for the use of numbers at least on an ordinal scale.

\section{A standardised vulnerability assessment in eight steps}

The concept proposed here is an operational framework to assess vulnerability built on a set of impact chains and indicators that are co-developed with stakeholders. This concept is based on a methodological framework that was first applied for climate change related vulnerability assessments in the Alpine region (Schneiderbauer et al., 2013). The approach allows for the integration of different data sources such as measurements, models, surveys, and expert-based as well as participatory appraisals, and makes value-based aspects explicit and participative. The framework, with all its elements and steps, is strictly oriented towards its suitability for adaptation planning.

The outcomes are assessments of relevant sub-systems at a level of detail that fits to the adaptation planning in a given setting, and not one single standardised composite indicator for vulnerability.

The temporal reference of the assessment preferably includes current vulnerability to present climate extremes or trends as well as vulnerabilities for different future time slices (e.g. 30-year climatological mean "valid" for 2030 or 2050). The inclusion of current climate vulnerability allows for the exploitation of stakeholder observations and experiences concerning the root causes of observed climate impacts. The knowledge of current and future climate vulnerability is an important entry point for planning effective adaptation measures. The Sourcebook presents the assessment approach in eight steps (Table 2).

\subsection{Step 1 - preparing the vulnerability assessment (VA)}

The objective of this first step is to clarify the context of the VA and to define its particular scope. The context includes the objective (e.g. development of a national adaptation strategy), the existence of studies and knowledge (including data and methods), and the target group of the VA, as well as the availability of resources (persons, time, and money). This first working step of "scoping" results in decisions on topics (sectors, social groups to be considered), the spatial scale (e.g. national, provinces), the temporal scale (e.g. present or future climate scenarios) and the methodological approach to be applied. Finally, a VA implementation plan should define all concrete activities and tasks. The authors recommend already involving stakeholders in this phase and organising the scoping through a kick-off workshop.

\subsection{Step 2 - developing impact chains}

Impact chains are conceptual models describing climate impact as cause-effect relationships within a socio-ecological system. Impact chains are the author's major approach for the question of how to operationalise vulnerability. Applying the IPCC AR4 concept strictly (Section 2) the Sourcebook's impact chains describe the relations between the components of vulnerability, which are the climate signals (exposure - E), the system's sensitivity (S) towards these signals and its adaptive capacity (AC). Intermediate outputs are potential impacts (PI), as a function of E and S. The final output is Vulnerability (V), a function/ 
Step

1 Preparing the Vulnerability Assessment

2 Developing Impact Chains

3 Identifying and Selecting Indicators

4 Data Acquisition and Management

5 Normalization and Threshold Definition

6 Weighting and Aggregation of Indicators to Vulnerability Components

7 Weighting and Aggregating of Vulnerability Components

8 Presenting the Outcomes of the Vulnerability Assessment
Objective

Definition of objective and scope. Estimate of resources needed

Definition of the potential impacts addressed in the vulnerability assessment; development of impact chains Selection of indicators for the assessment, based on the relevant factors from Step 2

Guidance on data collection, database construction and linking relevant data to the chosen indicators

Transfer of the different data sets into unit-less values on a common scale

Demonstrate how to assign weights to the various indicators and how to aggregate indicators to vulnerability components Aggregate the vulnerability components exposure and sensitivity to potential impact and potential impact and adaptive capacity (AC) into composite vulnerability indicator (s)

Summary and presentation of the findings of the vulnerability assessment
Vulnerability sourcebook and climate impact

Table 2.

Eight steps of the vulnerability assessment

relationship of PI and AC. For each vulnerability, component more than one factor can be defined. Furthermore, for each system more than one vulnerability can be defined. In the author's approach, each vulnerability refers to a particular potential impact. The vulnerability of the total system, particularly in multi-sectorial studies, should be subdivided into multiple meaningful vulnerabilities. Figure 2 illustrates a simplified impact chain for one particular vulnerability ("vulnerability of village farmers to erosion and land degradation") from the Pakistan case study.

While impact chains should build on existing scientific knowledge, it is also recommend developing impact chains in a participatory manner together with experts and key stakeholders in order to match them with the concrete adaptation context. In the cases studies, the authors started from a broad collection of potential climate impacts on a given system, which were narrowed down in a participatory prioritisation process by using standard pinboard moderation techniques (Figure 3).

Consequently, for all relevant impacts, impact chains were set-up. To be applicable in an operational assessment scheme, impact chains need to be further reduced, simplified and fine-tuned in an iterative process taking into account relevance, scientific knowledge as well as potential indicators for a single factor. If data availability seems to be poor for a prioritised factor, it is recommended nevertheless keeping this factor in the chain and searching either for a proxy indicator or the consideration of an expert-based evaluation in the subsequent steps. The underlying hypothesis of this more holistic approach is that purely data driven approaches can only cover a certain portion of vulnerability, often restricted to some direct impacts whilst skipping important aspects of sensitivity and adaptive capacity.

Adaption measures could already be conceptually integrated into the chains during this phase. In the example of Figure 2, reforestation or an increase of rainwater harvesting could decrease vulnerability. Impact chains are not just the backbone of the VA, but already a result per-se, as they conceptualise the causes of climate vulnerability within a systematic and agreed approach. 

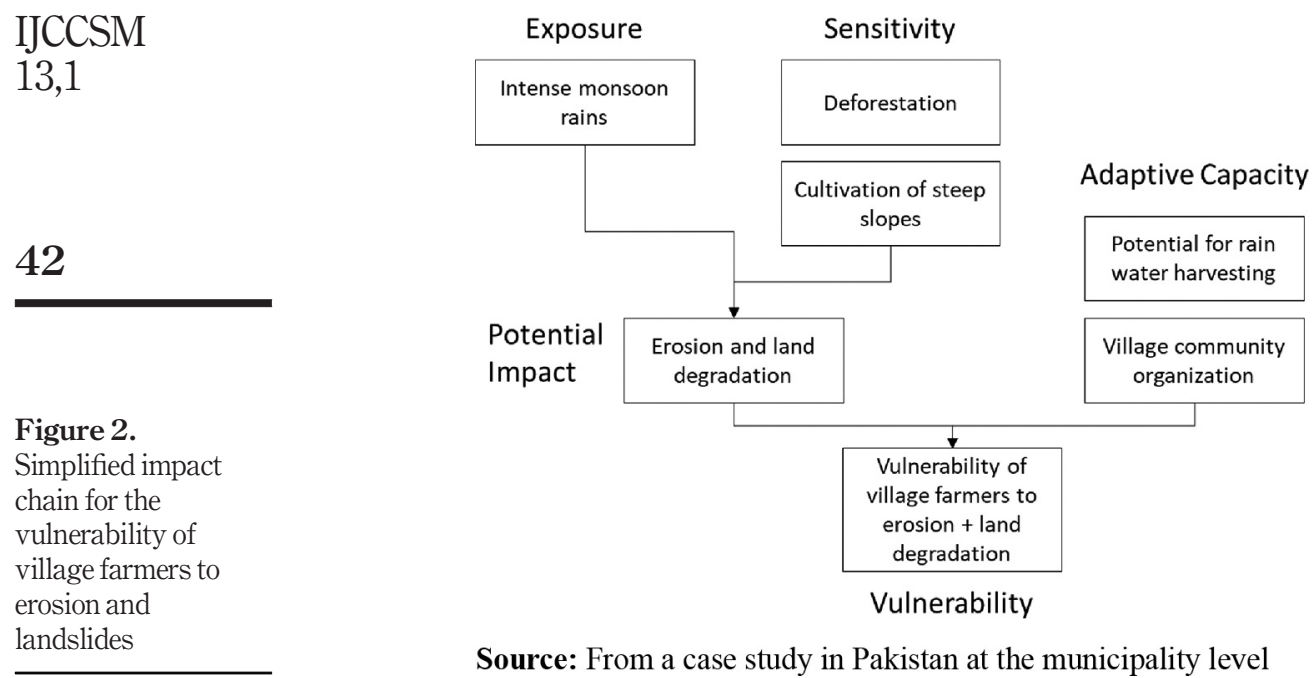

Source: From a case study in Pakistan at the municipality level

\subsection{Step 3 -identifying and selecting indicators}

While impact chains are the "back-bone" of the assessment approach, indicators are the "flesh on the bones". Usually, only a few potential impacts can be assessed through existing models (e.g. in hydrology) in most cases appropriate indicators have to be identified for all relevant factors of the impact chains and connected to the three components of vulnerability (exposure, sensitivity, adaptive capacity). The choice of appropriate indicators depends very much on the scope of the study and on data availability. However, good indicators share common attributes in being relevant, measurable, practical and clearly interpretable in the direction of climate vulnerability (e.g. high values contribute to a high vulnerability). "Measurable" means that it must be possible to assign categorical or ordinal value to an indicator. For example, "poverty level in the population" is not a sufficiently explicit indicator for measuring the factor "poverty". A good indicator instead would be "percentage of households on income of less than US $\$ 1$ per day". For an overview of indicators used in the three case studies (Tables 4-6).

\subsection{Step 4-Data sources and data acquisition}

Tables 4-6 illustrate that data sources and methods of data acquisition for indicators depend very much on data availability and the set-up of the vulnerability assessment (scale, resources and temporal reference). For exposure indicators (meteorological parameters), data can stem from national weather services (for the past) and climate model runs (for the past and future). Today, the model results from General Circulation Models (GCM), which have been used within the IPCC AR5 reports (IPCC, 2013), are available through the CMIP5 - Coupled Model Inter-comparison Project (Taylor et al., 2012). For many regions in the world, downscaled climate model runs are available through Regional Climate Models (RCMs), for instance through the Coordinated Regional Climate Downscaling Experiment (CORDEX) (Giorgi et al., 2009). CORDEX scenarios are based on climate model ensembles representing different combinations of GCMs and RCMs. In particular, this ensemble approach allows for a consideration of all aspects of model uncertainty in climate scenarios (Tebaldi and Knutti, 2007). Despite all these existing data, the author's experience in the case studies has shown that a common limitation for sub-national 


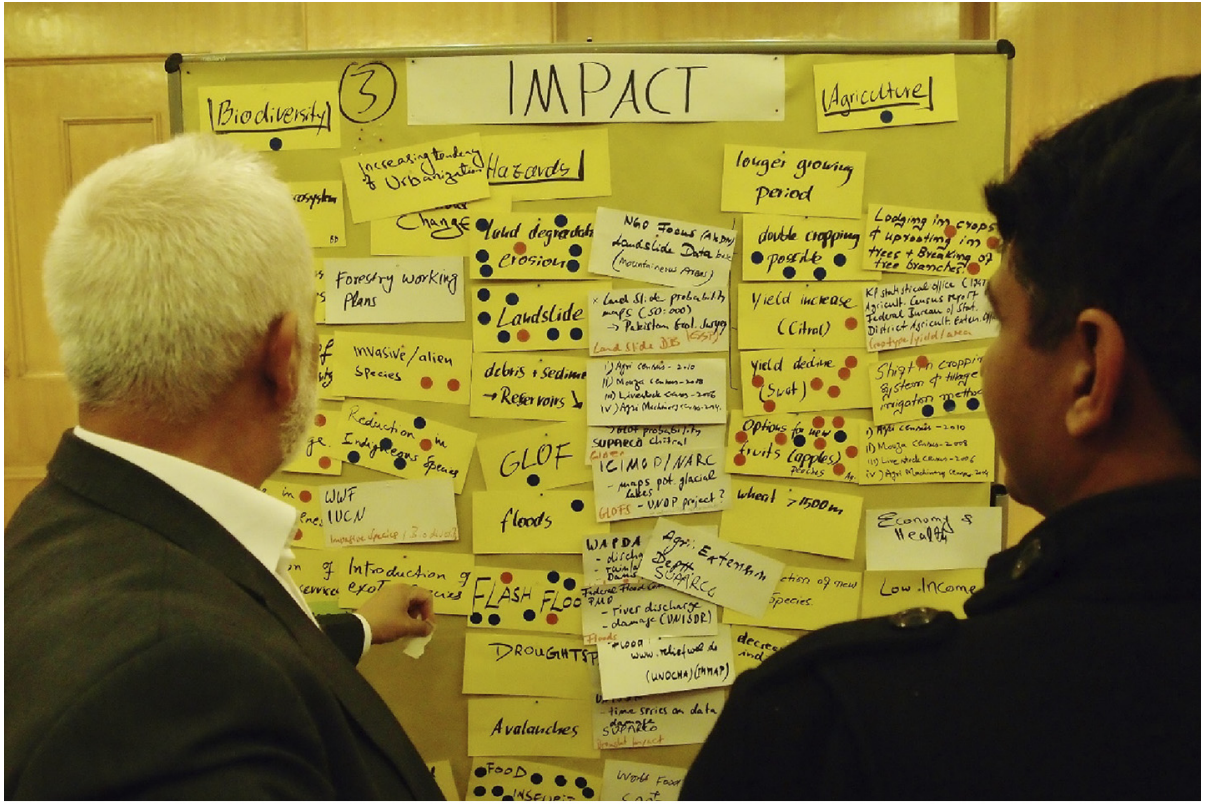

Source: (C) Marc Zebisch

applications remains the availability and consistency of meteorological data. Time series are often sparse, not corrected and inconsistent. While climate model runs don't face such problems, their limitations often consist of missing or dissatisfactory bias-correction to the local conditions or missing climate ensembles. Furthermore, the processing and analysis of climate scenarios requires an expertise which can often only be found at the level of national weather services or bigger national or international research institutions.

For sensitivity, standardised globally available data sources exist, such as for land cover from remote sensing (e.g. ESA GlobCover data set (Arino et al., 2010)) or modelled data on population counts and density (e.g. WorldPop data (Stevens et al., 2015)). Adaptive capacity largely builds on proxy indicators.

For the sensitivity and adaptive capacity, expert judgement is often an alternative way for addressing indicators that otherwise cannot be assessed. This is most often the case at a very local level - such as a village or community level - that is rarely covered by detailed statistical data, and where the climatic and hydrological characteristics are too specific to be captured by modelling. This local knowledge - obtained by using participative methods as well as scoring and ranking - can be used to either complement or replace surveys. However, information gathered in this way is always subjective. Moreover, it is difficult to repeat and is limited in precision and spatial distinction. A balanced selection of experts and stakeholders will increase the chances of obtaining meaningful results (Fritzsche et al., 2015).

\subsection{Step 5 - normalisation and threshold definition}

To be able to compare and aggregate any indicators it is necessary to transform them into a common unit-less value scheme. This is on the one hand a mathematical operation
Vulnerability sourcebook and climate impact

43

Figure 3.

Collection of potential climate impacts related to

biodiversity, natural hazards and agriculture, gathered during a training session for the Pakistan case study 
IJCCSM

13,1

44

(normalisation) but at the same time an important value-based decision. Objective information (e. g. number of days with heavy rain events) is transformed into an explicit interpretation of the importance of a specific parameter value on the vulnerability of the system. The authors propose using a range from 0 to 1 (equals $0 \%$ to $100 \%$ ), with " 0 " meaning: "uncritical, optimal state" and " 1 " meaning "critical, function of system threatened". The decision on thresholds for " 0 " and " 1 " should be taken context specific (for the specific case and the specific vulnerability). The way in which indicator data is transformed into this range depends on the scale level (e.g. metric, ordinal, nominal level). Metric data could be normalised through a modified min-max transformation, setting a maximum for a parameter value that would lead to a critical state and a minimum to a value that is related to an uncritical state. Ordinal or nominal values need to be transformed by transfer schemes, which need to be thoroughly co-developed with stakeholder and experts for the particular system under consideration. For an easier communication, school grade-type schemes (such as values from 1-5) could be used and transformed into the $0-1$ scheme afterwards. See Figure 4 for an example of a transfer scheme used in the Burundi case study. The scheme transfers ordinal values (classes of population density) through school grades into the unit-less scheme from 0 to 1 . Thresholds for population classes stemmed from a discussion with local experts on the carrying capacity and the sustainability of land-use related to population density. The resulting transfer scheme is specific to the country of Burundi and would look very different for regions in other climate zones.

\subsection{Step 6 -weighting and aggregation of indicators to vulnerability components}

In the next step, indicators are aggregated within each single vulnerability component (exposure, sensitivity and adaptive capacity) (Figure 5) to composite indicators. Due to normalisation in the step before, indicators can be mathematically aggregated in a weighted aggregation scheme. Weights can be applied if experts and stakeholders consider factors within one vulnerability component as not of equal importance. Actually, in two of the three case studies presented here (Burundi, Pakistan), it was decided together with the stakeholder not to apply any weighting. Instead, the normalisation and threshold definition of each factor (see step 5) was done in a way that " 1 " = critical stands for a similar contribution to the overall risk. In Bolivia, a study on a very local scale, stakeholders decided for weighting for certain adaptive capacity factors. There is a huge range of potential aggregation methods from simple weighted arithmetic mean to all variants of Pythagorean means, such as a weighted geometric mean or weighted harmonic mean. Whilst an arithmetic mean tends to level out extreme values, it has the advantage of simplicity, which makes it easy to understand and interpret. Geometric and harmonic means, in contrast, have the advantage of a lower compensability of low values. In the cases presented here, the authors applied arithmetic mean for the bottom-up participatory case studies (e.g. in Pakistan), where the number of factors were low, and comprehensibility was important. For studies that are

Figure 4.

Example of a transfer scheme from the Burundi case study

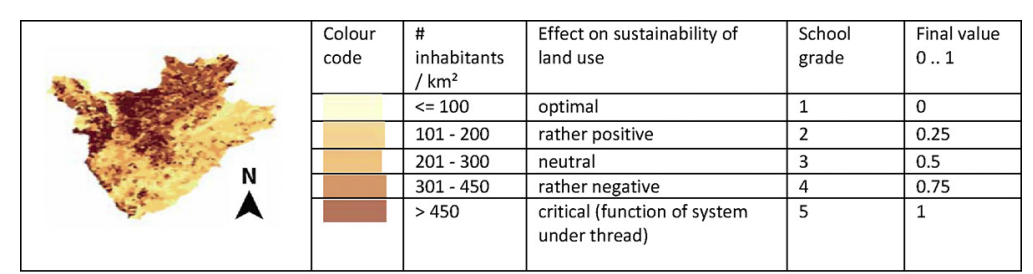

Note: Evaluation of population density and its effect on the sustainability of land use as one factor for sensitivity 


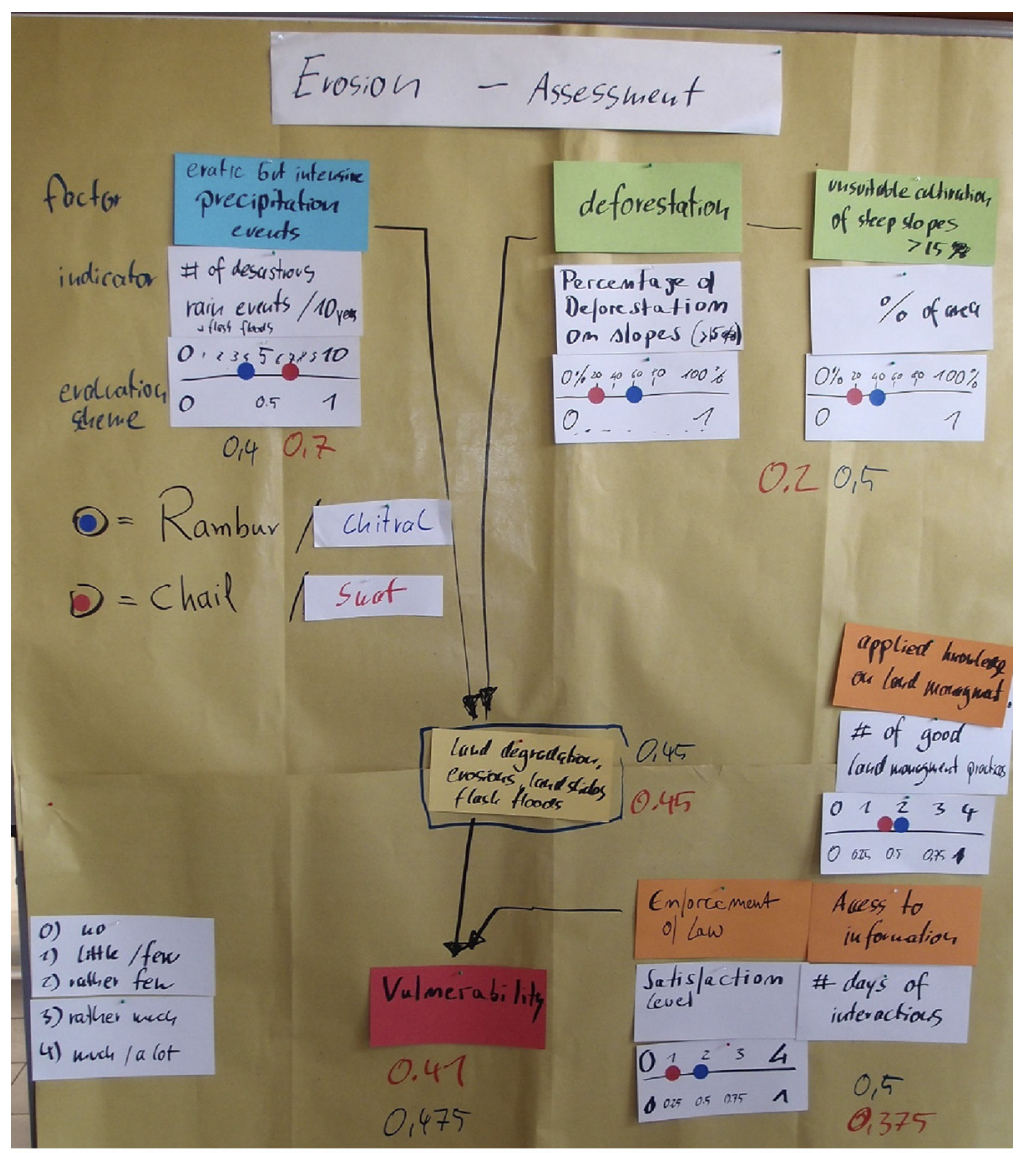

Notes: The impact chain was generated during a workshop in Pakistan. Indicators were identified and a preliminary expert assessment carried out Source: (C) Marc Zebisch
Vulnerability sourcebook and climate impact

45
Figure 5. Simplified impact chain for vulnerability towards land degradation, erosion, landslides and flash floods, due to heavy rain events

more data driven and cover many factors, a geometric or even harmonic mean might be more recommendable. The final output of step 6 is an evaluation for each of the components of vulnerability.

\subsection{Step 7 -weighting and aggregating of vulnerability components}

In a last aggregation step, the single components are aggregated to a composite vulnerability indicator for each vulnerability, applying the same aggregation method that has been chosen for step 6 (Figure 5). If impact chains have been built for more than one vulnerability, single vulnerabilities could also be further aggregated using the same method, for instance to one vulnerability per sector. The authors do not recommend aggregating the results to an overall vulnerability score, as the interpretability will become difficult and the information content for adaptation planning will be low. 


\section{IJCCSM \\ 13,1}

\subsection{Step 8-presenting outcomes}

There are numerous ways of presenting the outcomes of a vulnerability assessment. The most important means of presenting the results of the vulnerability assessment to an external audience is a vulnerability assessment report. The report will contain the results of the vulnerability assessment but also an explanation of the whole process, starting from the objectives and the scope. If the assessment was a spatially explicit assessment, results can be presented as vulnerability maps (see example from Burundi in Section 4). In other cases, they can be presented as tabular data, illustrated by spider web diagrams or similar means. It is important to complement the results of the semi-quantitative assessment with narratives, which include all the results from discussions, interviews, etc. which could not be squeezed into numbers and indicators. Finally, a relation to the adaptation context should be made explicit. This could be done by highlighting regional hot-spots or critical elements and social groups belonging to the system for adaptation planning.

\section{Results from case studies}

Here three case studies are presented, each with very different settings. Table 3 summarises the scope of the three case studies. Tables 4-6 list for each case study the most relevant factors, indicators and data sources used in the vulnerability assessment.

\begin{tabular}{|c|c|c|c|}
\hline & Bolivia & Pakistan & Burundi \\
\hline $\begin{array}{l}\text { Context }+ \\
\text { Purpose }\end{array}$ & $\begin{array}{l}\text { Assess vulnerability of } \\
\text { small farm holders and } \\
\text { evaluate effects of recent } \\
\text { adaptation measures }\end{array}$ & $\begin{array}{l}\text { Identify adaptation measures } \\
\text { and evaluate their influence } \\
\text { on the vulnerability of local } \\
\text { communities }\end{array}$ & $\begin{array}{l}\text { Identify national and local } \\
\text { hotspots for planning } \\
\text { adaptation measures }\end{array}$ \\
\hline Spatial scale & Village to individual farm & $\begin{array}{l}\text { Two districts of Swat and } \\
\text { Chitral+ village leve }\end{array}$ & $\begin{array}{l}\text { Nationwide, followed by a } \\
\text { more in-depth assessment at } \\
\text { local scale in identified } \\
\text { subnational hotspots }\end{array}$ \\
\hline $\begin{array}{l}\text { Temporal } \\
\text { scale }\end{array}$ & $\begin{array}{l}\text { Periods before and after } \\
\text { introduction of measures, } \\
\text { near future }\end{array}$ & $\begin{array}{l}\text { Vulnerability to current } \\
\text { climate variability and } \\
\text { climate extremes }\end{array}$ & $\begin{array}{l}\text { Three time periods: present, } \\
\text { 2031-2060, and 2071-2100 }\end{array}$ \\
\hline Relevant topic & $\begin{array}{l}\text { Climate change and water } \\
\text { supply in agriculture }\end{array}$ & $\begin{array}{l}\text { Climate change impacts on } \\
\text { agriculture and (agro-) } \\
\text { biodiversity }\end{array}$ & $\begin{array}{l}\text { Climate change impacts on } \\
\text { agriculture (production and } \\
\text { soil erosion) and health } \\
\text { (malaria prevalence) }\end{array}$ \\
\hline $\begin{array}{l}\text { Proposed } \\
\text { input }+ \\
\text { methods }\end{array}$ & $\begin{array}{l}\text { Combination of model- } \\
\text { based, data driven } \\
\text { approaches and expert } \\
\text { opinion method }\end{array}$ & $\begin{array}{l}\text { Expert-opinion method } \\
\text { conducted during a } \\
\text { stakeholder workshop, } \\
\text { participatory rural appraisal } \\
\text { (PRA) }\end{array}$ & $\begin{array}{l}\text { Combination of model-based } \\
\text { and participatory } \\
\text { approaches. Resulting maps } \\
\text { at the national level. } \\
\text { Quantitative analysis at the } \\
\text { national level, more } \\
\text { qualitative analysis at the } \\
\text { local level }\end{array}$ \\
\hline $\begin{array}{l}\text { Number of } \\
\text { external } \\
\text { stakeholders/ } \\
\text { experts } \\
\text { involved }\end{array}$ & $\begin{array}{l}6 \text { (including local water } \\
\text { engineers, experts on rural } \\
\text { development) }\end{array}$ & $\begin{array}{l}\sim 20 \text { (including local } \\
\text { agricultural extension } \\
\text { officers, met-office, ...) }\end{array}$ & $\begin{array}{l}\sim 30 \text { (representative from } \\
\text { national ministries }+ \\
\text { departments, universities, ..) }\end{array}$ \\
\hline Time needed & 10 months & 6 months & 11 months \\
\hline
\end{tabular}

Table 3.

Scope of the three case studies

\section{involved} . 


\begin{tabular}{|c|c|c|c|}
\hline \multirow{2}{*}{$\begin{array}{l}\text { Case study } \\
\text { Component }\end{array}$} & \multicolumn{3}{|c|}{ Bolivia - water scarcity for irrigation in agriculture } \\
\hline & Factor & Indicator(s) & Data source \\
\hline \multirow[t]{2}{*}{ Exposure } & Precipitation & monthly precipitation [mm] & Measurement (past) \\
\hline & Temperature & Tmin and $T \max \left[{ }^{\circ} \mathrm{C}\right] /$ month & Climate Scenarios (future) \\
\hline \multirow[t]{2}{*}{ Sensitivity } & Crop Type & $\begin{array}{l}\text { Type of crop, month of sowing, } \\
\text { area cultivated }\end{array}$ & $\begin{array}{l}\text { Field data (past) } \\
\text { Scenarios (future) }\end{array}$ \\
\hline & $\begin{array}{l}\text { Efficiency of } \\
\text { irrigation system }\end{array}$ & $\%$ area covered, water losses & Field data (past) \\
\hline $\begin{array}{l}\text { Potential Impact (if } \\
\text { modelled) }\end{array}$ & $\begin{array}{l}\text { Water availability for } \\
\text { crops }\end{array}$ & $\begin{array}{l}\text { Water availability for crops } \\
\text { [mm], }\end{array}$ & $\begin{array}{l}\text { agro-hydrological model } \\
\text { ABRO3.1 }\end{array}$ \\
\hline \multirow[t]{4}{*}{ Adaptive Capacity } & Resources & $\begin{array}{l}\text { Land availability } \\
\text { Technical Assistance } \\
\text { Access to information } \\
\text { Proximity to trade channels }\end{array}$ & $\begin{array}{l}\text { Expert judgments } \\
\text { (workshop output) }\end{array}$ \\
\hline & Governance & $\begin{array}{l}\text { Efficiency of farmer's irrigation } \\
\text { organization }\end{array}$ & \\
\hline & Knowledge & $\begin{array}{l}\text { Knowledge about new crops } \\
\text { Crop management knowledge } \\
\text { Adjustments to agricultural } \\
\text { calendar }\end{array}$ & \\
\hline & Technologies & $\begin{array}{l}\text { Soil management } \\
\text { Seed management } \\
\text { Plague and disease control }\end{array}$ & \\
\hline
\end{tabular}

Vulnerability sourcebook and climate impact

Table 4.

Factors, indicators and data sources for the Bolivia case study

\begin{tabular}{|c|c|c|c|c|}
\hline \multirow{2}{*}{$\begin{array}{l}\text { Case study } \\
\text { Component }\end{array}$} & \multicolumn{3}{|c|}{ Pakistan - erosion and land degradation } & \\
\hline & Factor & Indicator(s) & Data sources & \\
\hline Exposure & Intense monsoon rains & $\begin{array}{l}\text { \# of intense rain events/ } \\
10 \text { years }\end{array}$ & Measurements & \\
\hline Sensitivity & $\begin{array}{l}\text { Deforestation on steep } \\
\text { slopes } \\
\text { Cultivation on steep } \\
\text { slopes }\end{array}$ & $\begin{array}{l}\% \text { of deforestation on slopes } \\
>15^{\circ} \\
\% \text { or area of cultivation of } \\
\text { slopes }>15^{\circ}\end{array}$ & $\begin{array}{l}\text { Participatory Rural Appraisal } \\
\text { (PRA) }\end{array}$ & \\
\hline $\begin{array}{l}\text { Adaptive } \\
\text { Capacity }\end{array}$ & Rainwater harvesting & $\begin{array}{l}\% \text { of potential water } \\
\text { harvesting exploited by mud } \\
\text { ponds or cemented ponds }\end{array}$ & & $\begin{array}{r}\text { Table } 5 . \\
\text { Factors, indicators } \\
\text { and data sources for }\end{array}$ \\
\hline & $\begin{array}{l}\text { Village community } \\
\text { organization }\end{array}$ & $\begin{array}{l}\% \text { of villages which are part } \\
\text { of village communities }\end{array}$ & & $\begin{array}{r}\text { the Pakistan case } \\
\text { study }\end{array}$ \\
\hline
\end{tabular}

In all three case studies, at least two stakeholder workshops have been conducted. Stakeholder and experts were typically representatives from national ministries and departments, such as the Hydro-Met services, as well as representative at the local level (e.g. agricultural extension officers). In a first workshop, key impacts were identified, and impact chains developed in a participatory manner. Afterwards, data collection and surveys were conducted to populate indicators in a quantitative (e.g. climate data, erosion modelling) or qualitative manner (e.g. expert surveys on adaptive capacity). In a second workshop, results from the data collection were presented and assessed by experts, based on agreed assessment schemes, which were developed together with the external experts and stakeholders. This intermediate assessment was then aggregated and reviewed, first by the consultant team and then by the local experts in order to get to the final result. 


\section{IJCCSM 13,1}

Table 6.

Factors, indicators and data sources for the Burundi case study - vulnerability to erosion

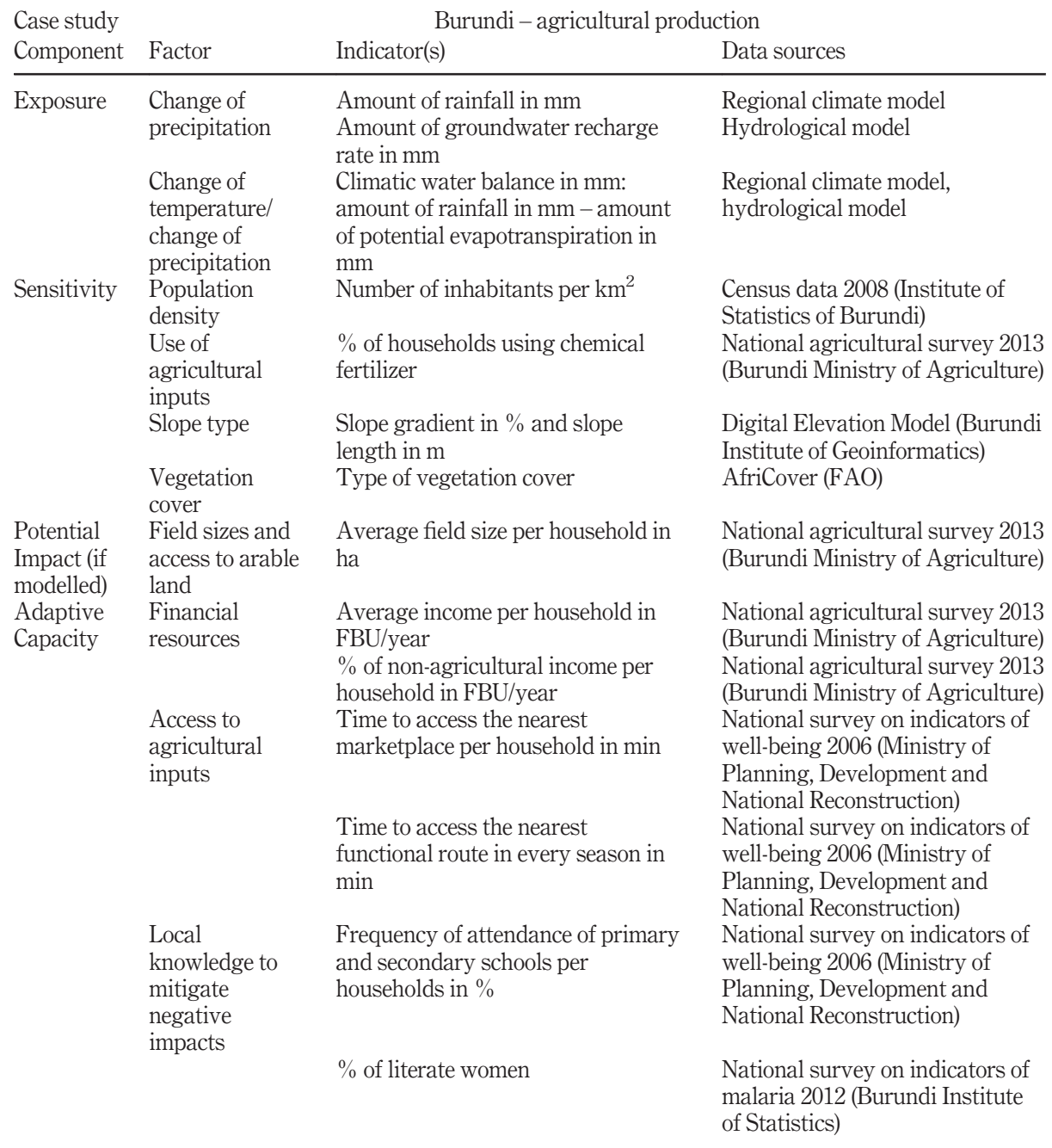

\subsection{Bolivia}

The community of Chullcu Mayu, Bolivia, is located on an altitude of $3500 \mathrm{~m}$ in the Cordillera Oriental, $75 \mathrm{~km}$ from the city of Cochabamba. The area of interest is a community of 97 peasant families, with an agricultural area of 61 ha. The problem for agricultural production in this region is water scarcity due to erratic rainfall and low efficiency in their traditional irrigation systems. With climate change, precipitation is projected to decrease further in this region. Within the Sustainable Agricultural Development Program (PROAGRO), Farmers in the Chullcu Mayu community have implemented a new irrigation system along with a training program and a farmer's organisation as a measure to adapt to current climate variability and future climate change. Hence, the objective of the 
vulnerability assessment was to quantify to what extent climate vulnerability has been reduced from a period without irrigation system $(1960$ - 1990) to the period after the introduction of the irrigation system $(1991-2011)$. For the Chullcu Mayu case study, it was possible to follow a mainly data driven approach. The impact of climate change and the irrigation system on water availability for agriculture was estimated quantitatively with and without the irrigation system. The estimation was based on climate data and hydrological data, and conducted with the help of the agro-hydrological model ABRO3.1 (Componente de Asistencia Técnica del Programa Nacional de Riego, 2002). Adaptive capacity was assessed by expert judgement for four single factors (Resources, Governance, Knowledge, Technologies). Within each factors a set of sub-factors was defined and assessed separately. For instance, the adaptive capacity in the field of "Knowledge" was subdivided into knowledge on introduction of new crops, knowledge on crop management, adjustment to agricultural calendar. See Figure 6 for the impact chains and Table 4 for the indicators. Further information on the Bolivia case study can be found in the annex of the Sourcebook (Fritzsche et al., 2015)

The results indicated, that the introduced adaptation measures have significantly lowered the vulnerability from 0.71 (rather negative, high vulnerability) before the introduction of the irrigation system (1960-90) to 0.21 (rather positive, low vulnerability) after the introduction (1991-2011), mainly by reducing the potential impact through increasing the proportion of cropping area with sufficient water supply, but also by increasing the adaptive capacity of the system. For adaptive capacity the most relevant factors were improvements in governance (introduction of a farmers organisation) and knowledge (through training programs).

4.1.1 Pakistan. The two districts of Swat and Chitral are located in the Pakistani Hindukush mountains and cover an area of roughly $20,000 \mathrm{~km}^{2}$ with around 2.5 million inhabitants. In the last decades, climate extremes in combination with deforestation and inappropriate land management (cultivation of steep slopes without erosion protection, unsuitable crops) posed threats to food security and ecosystems. Here, an explorative vulnerability assessment with a focus on climate change impacts on agriculture, forestry and biodiversity, was conducted by a local consultant (trained by the authors) for 10 villages within the region (Hussain, 2014). The assessment intended to support the identification and implementation of community-driven and ecosystem-based adaptation measures to climate

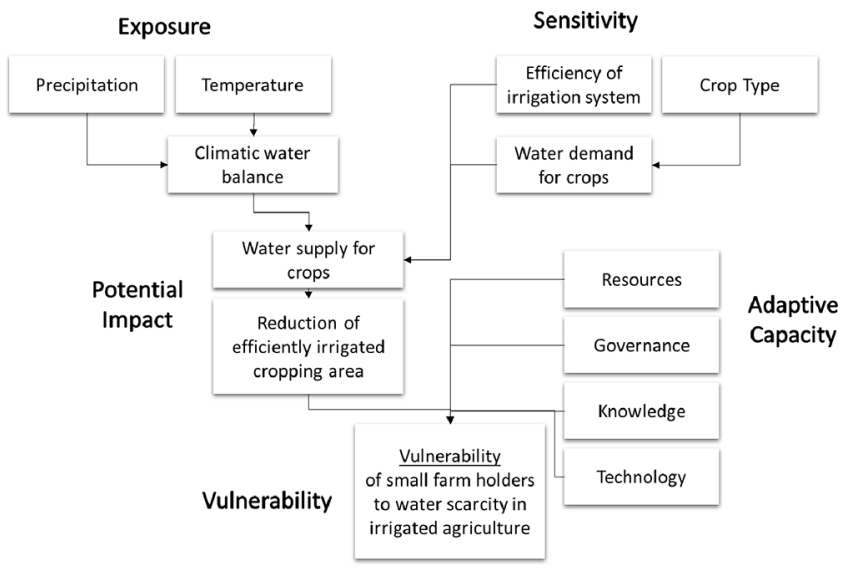

Vulnerability sourcebook and climate impact

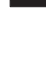


IJCCSM

13,1 change in the framework of the GIZ project "Conservation and Sustainable Management of Biodiversity in Khyber Pakhtunkhwa (BKP)". The Pakistan case study was focussing on the current vulnerability of village farmers and their agricultural land to erosion and landslides. The identified factors (Table 5) which lead to erosion and land degradation were; intense monsoon rains, for exposure; deforestation and cultivation on steep slopes, for sensitivity; and the extent of rain-water harvesting measures to prevent land degradation in dry periods as well as the quality of village community organisation, for adaptive capacity. Factors were identified and assessed separately for the two districts in a participatory way using scores (from 0 to 1001) in one stakeholder workshop with national and local experts and complemented by a Participatory Rural Appraisal (PRA) undertaken by a local consultant within selected communities.

The results of the assessment indicate that the most important components for understanding the vulnerability of and the difference between the two regions is sensitivity and adaptive capacity and not the climate signal itself. According to the experts, the single most important factor contributing to the vulnerability of the region is deforestation (rated by the experts in one region as $0.75=$ "rather critical" on a scale from $0=$ "optimal" to $1=$ "critical", based on an estimate of deforestation in the region). But also, the lack of appropriate practices such as rainwater harvesting, were found as critical. Based on the findings of the vulnerability assessment, several recommendations to reduce climate vulnerability were developed, such as reforestation with broad leaved indigenous trees, a better protection of gullies, and construction of small water reservoirs and check dams, or capacity building measures such as awareness raising on appropriate land and water management.

4.1.2 Burundi. Burundi lies in the centre of Africa and is one of the smallest countries on this continent. It has one of the highest population densities worldwide, with approximately 11 million people living in an area of approximately $28,000 \mathrm{~km}^{2}$. A large part of Burundi's population lives in poverty and about $90 \%$ of Burundians are dependent on subsistence farming. The vulnerability assessment in Burundi focussed on the soil and water resources as crucial factors for both the agriculture sector and erosion processes. A more detailed description of methods and results are report in Schneiderbauer et al., 2020. For vulnerability to erosion, 14 indicators for the three components of vulnerability were identified (Table 6) and processed to GIS information layers. The indicators selection has been a two-step procedure. First, potential indicators were identified by local scientists and practitioners during a 2-daysworkshop. Following, a final selection was made by a core group of local experts taking into consideration the criteria relevance, analytical soundness, timeliness, accessibility, and clarity. Results were first aggregated for each component. Finally, all three components were aggregated into one vulnerability map (Figure 7). The results informed the GIZ - led technical cooperation project ACCESS (Adaptation au changement climatique pour la protection des ressources en eau et sol) that deals with climate change impacts on soil and water resources, as well as adaptation priorities at various scales (from local to national).

The entire assessment procedure was carried out with strong stakeholder and local expert participation who were able to contribute at two different levels of intensity. A wider group of actors participated at four workshops organised during the 11 months period of the main project work. A smaller group of selected core experts accompanied and advised the project more intensively and more frequently throughout the project work by means of meetings, which were arranged according to project needs.

The vulnerability assessment was based on both quantitative and qualitative approaches. Quantitative methods comprised climate and hydrological modelling as well as spatial analyses of various statistics. Qualitative methods complemented the quantitative 


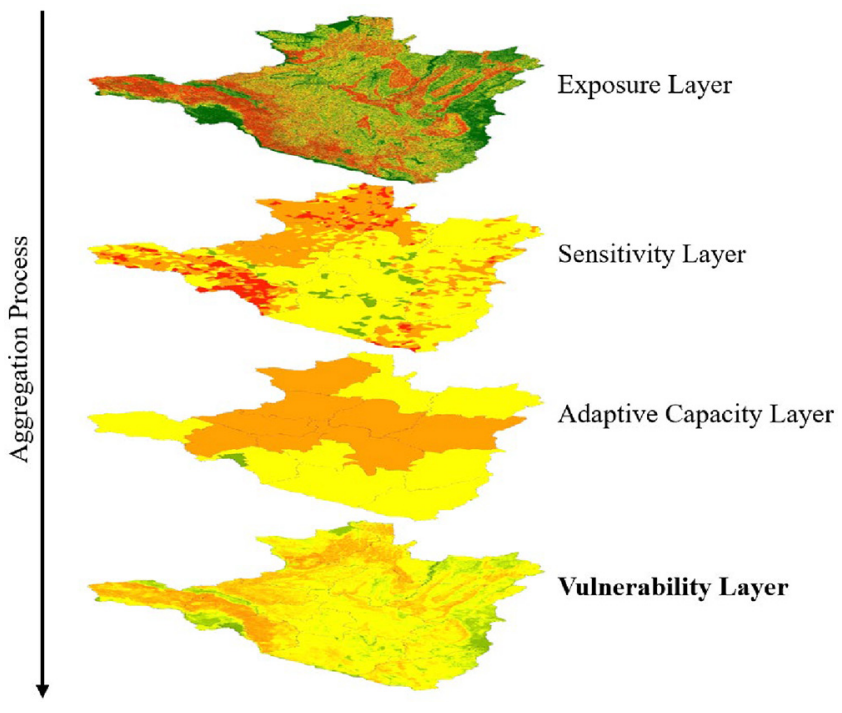

Vulnerability sourcebook and climate impact

results and allowed for the generation of context specific assessment rules. The assessment of the vulnerability to erosion was based on (1) the results of the model RUSLE (Revised Universal Soil Loss Equation) in which the bio-physical parameters of precipitation, temperature, vegetation and relief were incorporated and (2) the social-economic parameters linked to population, wealth and knowledge.

The core working steps of the vulnerability assessment at national scale comprised:

- climate and hydrological modelling;

- the development of climate impact chains;

- the selection, classification and aggregation of vulnerability indicators; and

- the generation of vulnerability maps.

The Burundi study showed that the country's erosion vulnerability hotspots are located in the northern and particularly the north-western part of Burundi, whilst vulnerability to drought is highest in the northeast and southeast of the country. The assessment in Burundi revealed that in addition to the selection of suitable indicators, a key challenge of the applied methodology is to evaluate the relevance of certain indicator values for vulnerability. That is, the allocation of the indicator values to certain classes associated with lower or higher vulnerability values is a crucial task, which is especially difficult for sensitivity and adaptive capacity indicators, as those factors are often less tangible. For example, in the case of the indicator "per cent of literate women" it is difficult to define the threshold of a percentage value that distinguishes between classes defining different degrees of adaptive capacities. In the case of Burundi, this problem was addressed by integrating local knowledge and expertise in order to obtain a meaningful classification of the various input indicators.

\section{Lessons learnt from case studies}

In addition to the experiences collected from the three case studies presented in this paper, the authors systematically collected feedback on the sourcebook approach in 
IJCCSM

13,1

2018 as part of an internal GIZ project using structured interviews with nine GIZ experts as well as external consultants which have applied the sourcebook. Results have shown that the sourcebook methodology is appreciated by development cooperation organisations as well as by stakeholders that is local experts and decision makers, as well as civil society organisations but also revealed limitations and bottlenecks.

Stakeholders perceived particularly the concept of impact chains as very helpful. According to their feedback, impact chains helped to obtain a clear picture of the links between climate change, key vulnerabilities and the complex web of underlying causes and effects. They appreciated the participatory approach, which often revealed the very specific vulnerabilities of their system and led to an agreed understanding of their climate vulnerability. Based on the impact chains, targeted discussions on potential entry points for adaptation measures were already fostered.

The fact that the actual vulnerability assessment is based on a set of specific indicators that are selected in accordance with the specific impact chains and not on any generic indicator scheme, supported the acceptance of the assessment approach. Furthermore, the mixed-method approach, which allows for the integration of quantitative, data driven approaches (e.g. for climate data) with more expert based assessments in a common assessment scheme, was very well accepted.

The discussion about the data required for the climate, land-use, ecosystem, as well as socio-economic aspects contributed to an increased knowledge of local stakeholders concerning existing and publicly accessible data sets (such as climate scenarios or data on land cover).

However, the authors also faced challenges during the course of the assessment. An initial challenge was the strong requirement for resources and experience for a data driven analysis, particularly if it was spatially explicit (such as the Burundi case). This included accessing, handling and analysing climate data and climate scenarios, impact models (such as hydrological models), as well as the quality control of socio-economic data. In practice, accessing and sharing data across different ministries, agencies and other parties created a bottleneck as data sharing policies and agreements were required and these took time to set up.

A second challenge is related to a discussion about the objectivity or replicability of qualitative assessment approaches. In all the case studies presented it became evident that a purely data driven approach could not cover the most relevant potential impacts. As a result, the inclusion of more qualitative approaches based on expert judgement and narratives was a very important element. However, it is challenging to make the process of such an evaluation as representative as possible by including enough people, having a good mix of stakeholder and experts, and asking the right questions, as well as correctly evaluating the answers. Expert-based assessments also have their drawbacks if the assessment needs to be repeated after a certain period of time to monitor the success of an adaptation activity. On the other hand, it can be argued that data-driven approaches also lack objectivity and that only their integration with expert based methods allows for the representation of many of the most important aspects of vulnerability in a given context.

A third challenge concerns the value-based character of any risk and vulnerability assessment. The process of the assessment is made up of many decisions that are not (solely) based on scientific knowledge, expertise or experience. These decisions need to take into consideration the political, societal, cultural and economic priorities within the local context. The local stakeholders and experts involved in the studies 
often hesitated in taking such decisions. The value-based character of an assessment is also reflected in a more technical component during the assessment procedure itself. The transformation of existing datasets (such as statistical data, physical model results) into a unit-less range of values (for example $0-1$ ) or respective classes (zero through to five) that allow for comparison and aggregation in order to describe a situation in a range between optimal and critical, is very demanding. Particularly for larger scale assessments (e.g. at the national level), where value-based decisions become a political issue, there is a relatively low competence and readiness of stakeholders to make such decisions. In the author's approach the fall-back solution in such cases was a min-max normalisation, which was not completely satisfying due to its pseudo-objectivity, as implicitly it still contained a value-based decision. The value-based aspect also becomes a challenge when a vulnerability assessment needs to be used for monitoring and thus repeated after a certain period of time. Is it possible and valid to maintain the value-based decisions, or should they be adapted to fresh developments?

A fourth challenge regarded the interpretability of results at higher levels of aggregation. Whilst the level of understanding and applicability was high at lower levels of aggregation (e.g. assessment of potential impact, assessment of adaptive capacity), the final aggregation step of potential impact and adaptive capacity to vulnerability was less easy to interpret, or even less helpful for adaptation activities. However, the aggregation into climate vulnerability is useful to identify spatial hotspots with high vulnerability, where several factors are in a critical state, and for comparative studies across different regions.

\section{Applying the vulnerability sourcebook to the AR5 concept of climate risk}

After the publication of the Vulnerability Sourcebook in 2014, the IPCC-AR5 WII report (Field et al., 2014) introduced a new concept of "climate risk", which is closer to the disaster risk community than the AR4 concept. The Risk Supplement to the Vulnerability Sourcebook (Zebisch et al., 2017) explains how the Sourcebook concept can be applied to the new AR5 climate risk concept.

The AR5 risk concept does not only introduce new terms and new definitions for old terms but follows a slightly different philosophy (Figure 8).

In the AR5 concept, hazard is the potential occurrence of a physical (meteorological or climate) event or trend or physical impact that may cause harm such as: loss of life, injury, negative health impacts, as well as damage and loss of property, infrastructure, livelihoods,
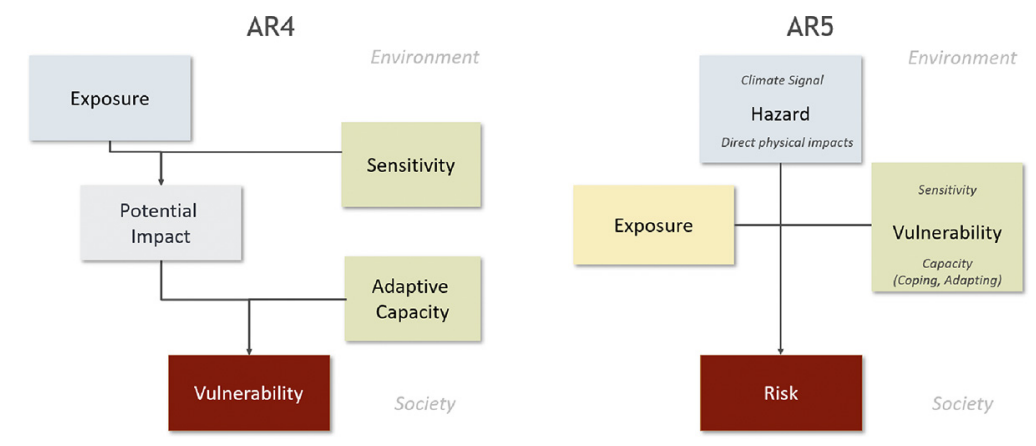

Source: From Zebisch et al. (2017)
Vulnerability sourcebook and climate impact

53

\section{(1)}


IJCCSM

13,1

ecosystems and environmental resources. Vulnerability is the predisposition to be adversely affected. Vulnerability (in AR5) encompasses a variety of concepts including sensitivity or susceptibility to harm and lack of capacity to cope and adapt. Exposure is the presence of people, livelihoods, species or ecosystems, environmental functions, services and resources, infrastructure or economic, social, or cultural assets in places and settings that could be adversely affected. Risk is the potential for consequences where something of value is at stake and where the outcome is uncertain [...]. Risk results from the interaction of vulnerability, exposure, and hazard (Field et al., 2014). In the Risk Supplement the authors conclude that the Vulnerability Sourcebook concept with impact chains as its core concept can be applied almost unchanged following the same eight steps and the indicator-based approach. The main modification is to assign factors to AR5 risk components Hazard, Exposure and Vulnerability when building impact chains.

\section{Conclusion}

It is concluded from the application of the assessment approach in very different settings, that an indicator-based vulnerability assessment building on a systemic approach, which is co-developed and co-performed with the respective stakeholders, is a very useful tool for adaptation planning and monitoring. When developed with care, it can represent the right balance between the demand to "measure" vulnerability and the consideration of the unmeasurable aspects of vulnerability. Challenges include the replicability of the assessment based on data availability, decisions to be made considering non-scientific objectives of political, social, economic or cultural type, the interpretability and comparability of aggregated results. Future developments to improve the approach and to make it more replicable could include a good selection of robust and simple standard assessment approaches and standard impact chains for common climate impacts in the context of developing countries (such as agricultural drought, health issues, sea-level rise), as well as a clearer agreement on the reference of assessment (what does 100\% Vulnerability mean?). Furthermore, the relatively linear and sectorial approach of impact chains could be widened to impact webs, which would include feedback relations and cross-connections.

Meanwhile, the "Risk supplement" to the Vulnerability Sourcebook has been published (Zebisch et al., 2017), which transfers the assessment approach with impact chains to the latest IPCC AR5 concept. Another guideline focuses specifically on how to apply the impact chains approach for climate risk assessment within the context of Ecosystem based Adaptation - EbA (Hagenlocher et al., 2018). The Sourcebook approach has been applied in over twenty countries and has been translated into Spanish, French and Arabic. More documents, guidelines and other resources related to the Sourcebook can be found online at AdaptationCommunity.net (Deutsche Gesellschaft für Internationale Zusammenarbeit - GIZ, 2019).

\section{References}

Adger, W.N. Brooks, N. Bentham, G. and Agnew, M. (2004), "New indicators of vulnerability and adaptive capacity", Technical Report 7, available at: http://citeseerx.ist.psu.edu/viewdoc/ download?doi=10.1.1.112.2300\&rep=rep1\&type $=$ pdf

Adger, W.N. (2006), "Vulnerability", Global Environmental Change, Vol. 16 No. 3, pp. 268-281, doi: 10.1016/j.gloenvcha.2006.02.006. 
Adger, W.N., Brown, I. and Surminski, S. (2018), "Advances in risk assessment for climate change adaptation policy", Philosophical Transactions of the Royal Society A: Mathematical, Physical and Engineering Sciences, Vol. 376 No. 2121, doi: 10.1098/rsta.2018.0106.

Arino, O., Perez, J.R., Kalogirou, V., Defourny, P. and Achard, F. (2010), “Globcover 2009”, Proceedings of the ESA Living Planet Symposium, pp. 1-3.

Baettig, M.B., Wild, M. and Imboden, D.M. (2007), “A climate change index: where climate change may be most prominent in the 21st century", Geophysical Research Letters, Vol. 34 No. 1, doi: 10.1029/ 2006GL028159.

Vulnerability sourcebook and climate impact

Brooks, N. (2003), "Vulnerability, risk and adaptation: a conceptual framework", Tyndall Centre for Climate Change Research, 38, p. 20, available at: papers2://publication/uuid/D2016620-F4DE4C0A-BE4B-78E8F2701438.

CARE (2009), "Climate vulnerability and capacity analysis - handbook", available at: http:// careclimatechange.org/wp-content/uploads/2014/12/CVCA_EN.pdf

Componente de Asistencia Técnica del Programa Nacional de Riego (2002), Cálculo del ÁreaBajo Riego Óptimo - ABRO, Cochabamba.

Crichton, D. (1999), “The risk triangle”, in Ingleton, J. (Ed.), Natural Disaster Management, Tudor Rose, London.

de Sherbinin, A. (2014), "Climate change hotspots mapping: what have we learned?", Climatic Change, Vol. 123 No. 1, pp. 23-37, doi: 10.1007/s10584-013-0900-7.

Dessai, S. and Hulme, M. (2004), "Does climate adaptation policy need probabilities?", Climate Policy, Vol. 4 No. 2, pp. 107-128, doi: 10.1080/14693062.2004.9685515.

Deutsche Gesellschaft für Internationale Zusammenarbeit - GIZ (2019), "Vulnerability/risk assessment, AdaptationCommunity.net", available at: www.adaptationcommunity.net/vulnerability-assessment/ vulnerability-sourcebook/ (accessed 9 July 2019).

Field, C.B., Barros, V.R., Dokken, D.J., Mach, K.J., Mastrandrea, M.D., Bilir, T.E., Chatterjee, M., Ebi, K. L., Estrada, Y.O., Genova, R.C., Girma, B., Kissel, E.S., Levy, A.N., MacCracken, S., Mastrandrea, P.R. and White, L.L. (Eds) (2014), Climate Change 2014: Impacts, Adaptation, and Vulnerability. Part A: Global and Sectoral Aspects. Contribution of Working Group II to the Fifth Assessment Report of the Intergovernmental Panel on Climate Change, Cambridge University Press, Cambridge, United Kingdom and New York, NY.

Fritzsche, K. Schneiderbauer, S. Bubeck, P. Kienberger, S. Buth, M. Zebisch, M. and Kahlenborn, W. (2015), "The vulnerability sourcebook", Edited by GIZ - Gesellschaft für internationale Zusammenarbeit. Eschborn, available at: www.adaptationcommunity.net/? wpfb_dl $=203$

Füssel, H.M. (2007), "Vulnerability: a generally applicable conceptual framework for climate change research", Global Environmental Change, Vol. 17 No. 2, pp. 155-167, doi: 10.1016/j. gloenvcha.2006.05.002.

Füssel, H.M. and Klein, R.J.T. (2006), "Climate change vulnerability assessments: an evolution of conceptual thinking", Climatic Change, Vol. 75 No. 3, pp. 301-329, doi: 10.1007/s10584-0060329-3.

Füssel, H.-M. (2010), "Review and quantitative analysis of indices of climate change exposure, adaptive capacity, sensitivity, and impacts", World Development Report, p. 34, doi: 10.1016/j. gloenvcha.2010.07.009.

GCF (2011), "Governing instruments".

Giorgi, F., Jones, C. and Asrar, G.R. (2009), "Addressing climate information needs at the regional level: the CORDEX framework", Bulletin - World Meteorological Organization, Vol. 58 No. 3, pp. 175-183. 
IJCCSM 13,1

GIZ (2014), "Stocktaking of national adaptation planninge”, available at: https:/gc21.giz.de/ibt/var/app/ wp342deP/1443/wp-content/uploads/filebase/ms/mainstreaming-tools/giz-2014_Factsheet-SNAPEN.pdf

Hagenlocher, M. Schneiderbauer, S. Sebesvari, Z. Bertram, M. Renner, K. Renaud, F. Wiley, H. and Zebisch, M. (2018), "Climate risk assessment for ecosystem-based adaptation - a guidebook for planners and practitioners", Bonn, available at: www.adaptationcommunity.net/wp-content/uploads/2018/06/gizeurac-unu-2018-en-guidebook-climate-risk-asessment-eba.pdf

Hinkel, J. (2008), "A framework for analysing methodologies of vulnerability assessments", in Patt, A., Schröter, D., de la Vega-Leinert, A.C. and Klein, R.J.T. (Eds), Environmental Vulnerability Assessment, Earthscan, London.

Hinkel, J. (2011), "Indicators of vulnerability and adaptive capacity: towards a clarification of the science-policy interface”, Global Environmental Change, Vol. 21 No. 1, pp. 198-208, doi: 10.1016/j. gloenvcha.2010.08.002.

Hussain, S.S. (2014), "Adapting to climate change: a new tool for communities", Appropriate Technology, Vol. 41 No. 3, p. 36ff, available at: www.approrpriate-technology.com

IPCC (2013), Climate Change 2013: The Physical Science Basis. Contribution of Working Group I to the Fifth Assessment Report of the Intergovern - Mental Panel on Climate Change, Cambridge University Press, Cambridge, United Kingdom and New York, NY.

Klein, R.J.T., Midgley, G.F., Preston, B.L., Alam, M., Berkhout, F.G.H., Dow, K. and Shaw, M.R. (2014), 16. Adaptation Opportunities, Constraints, and Limits, Assessment Report 5- Climate Change 2014: impacts, adaptation, and vulnerability. Part A: Global and Sectoral Aspects, pp. 899-943.

Lamhauge, N., Lanzi, E. and Agrawala, S. (2012), Monitoring and Evaluation for Adaptation: Lessons from Development Co-Operation Agencies, Paris.

Least Developed Countries Expert Group (2012), "National adaptation plans. Technical guidelines for the national adaptation plan process", Bonn, available at: https://unfccc.int/files/ adaptation/cancun_adaptation_framework/application/pdf/naptechguidelines_eng_high_ res.pdf

Maplecroft (2015), Climate Change and Environmental Risk Atlas 2015, Maplecroft, London.

Metzger, M.J. and Schröter, D. (2006), "Towards a spatially explicit and quantitative vulnerability assessment of environmental change in Europe", Regional Environmental Change, Vol. 6 No. 4, pp. 201-216, doi: 10.1007/s10113-006-0020-2.

O’Brien, K., Eriksen, S., Nygaard, L.P. and Schjolden, A.N.E. (2007), "Why different interpretations of vulnerability matter in climate change discourses", Climate Policy, Vol. 7 No. 1, pp. 73-88, doi: 10.1080/14693062.2007.9685639.

OECD (2015), "Toolkit to enhance access to adaptation finance", available at: www.oecd.org/env/cc/ ToolkittoEnhanceAccesstoAdaptationFinance.pdf

Oppenheimer, M., Campos, M., Warren, R., Birkmann, J., Luber, G., O’Neill, B. and Takahashi, K. (2014), IPCC-WGII-AR5-19. Emergent Risks and Key Vulnerabilities, Climate Change 2014: impacts, Adaptation, and Vulnerability. Part A: Global and Sectoral Aspects. Contribution of Working Group II to the Fifth Assessment Report of the Intergovernmental Panel on Climate Change, doi: 10.1017/CBO9781107415379.

Parry, M.L., Canziani, O.F., Palutikof, J.P., Linden, P. J.v.d. and Hanson, C.E. (Eds) (2007), Contribution of Working Group II to the Fourth Assessment Report of the Intergovernmental Panel on Climate Change, 2007, Cambridge University Press, Cambridge, United Kingdom and New York, NY.

Piontek, F., Müller, C., Pugh, T.A., Clark, D.B., Deryng, D., Elliott, J., González, F.D.J.C., Flörke, M., Folberth, C., Franssen, W. and Frieler, K. (2014), "Multisectoral climate impact hotspots in a warming world", Proceedings of the National Academy of Sciences, Vol. 111 No. 9, pp. 3233-3238, doi: $10.1073 /$ pnas.1222471110. 
Preston, A.B. Stafford-Smith, M. and Lee, B.L.B. (2009), "Framing vulnerability and adaptive capacity assessment: discussion paper, CSIRO climate adaptation flagship working paper", available at: www.csiro.au/files/files/ppgt.pdf

PROVIA (2013), "PROVIA guidance on assessing vulnerability, impacts and adaptation to climate change. Nairobi”, available at: www.unep.org/provia/Portals/24128/PROVIA_guidance_report_low_resolut ion.pdf

Schneiderbauer, S., Baunach, D., Pedoth, L., Renner, K., Fritzsche, K., Bollin, C., Pregnolato, M., Zebisch, M., Liersch, S., Rocío, M., López, R. and Ruzima, S. (2020), "Spatial-explicit climate change

Vulnerability sourcebook and climate impact vulnerability assessments based on impact chains. Findings from a case study in Burundi", Sustainability, Vol. 12 No. 16, submitted.

Schneiderbauer, S., Pedoth, L., Zhang, D. and Zebisch, M. (2013), “Assessing adaptive capacity within regional climate change vulnerability studies-an alpine example”, Natural Hazards, Vol. 67 No. 3, doi: 10.1007/s11069-011-9919-0.

Schröter, D., Cramer, W., Leemans, R., Prentice, I.C., Araújo, M.B., Arnell, N.W., Bondeau, A., Bugmann, H., Carter, T.R., Gracia, C.A. and Anne, C. (2005), "Ecosystem service supply and vulnerability to global change in Europe", Science (New York, N.Y.), Vol. 310 No. 5752, pp. 1333-1337, doi: 10.1126/science.1115233.

Stevens, F.R., Gaughan, A.E., Linard, C. and Tatem, A.J. (2015), "Disaggregating census data for population mapping using random forests with remotely-sensed and ancillary data”, PloS One, Vol. 10 No. 2, p. e0107042, doi: 10.1371/journal.pone.0107042.

Taylor, K.E., Stouffer, R.J. and Meehl, G.A. (2012), “An overview of CMIP5 and the experiment design”, Bulletin of the American Meteorological Society, Vol. 93 No. 4, pp. 485-498, doi: 10.1175/BAMS-D11-00094.1.

Tebaldi, C. and Knutti, R. (2007), "The use of the multi-model ensemble in probabilistic climate projections", Philosophical Transactions of the Royal Society A: Mathematical, Physical and Engineering Sciences, Vol. 365 No. 1857, pp. 2053-2075, available at: http://rsta.royalsocietypublishing.org/content/365/1857/ 2053.abstract

Thomalla, F., Downing, T., Spanger-Siegfried, E., Han, G. and Rockström, J. (2006), "Reducing hazard vulnerability: towards a common approach between disaster risk reduction and climate adaptation”, Disasters, Vol. 30 No. 1, pp. 39-48, doi: 10.1111/j.1467-9523.2006.00305.x.

UNDP (2010), "Mapping climate change vulnerability and impact scenarios", available at: http:// europeandcis.undp.org/uploads/public1/files/MappingCCVulnerabilitypublication-November2010. pdf

UNFCCC (2013), "The state of adaptation under the united nations framework convention on climate change - thematic report. Bonn", available at: http://unfccc.int/files/adaptation/ cancun_adaptation_framework/adaptation_committee/application/pdf/ac_2013_report_ low_res.pdf

United Nations Department of Humanitarian Affairs (1992), Internationally agreed glossary of basic terms related to disaster management, United Nations.

Wolf, S., Hinkel, J., Hallier, M., Bisaro, A., Lincke, D., Ionescu, C. and Klein, R.J.T. (2013), "Clarifying vulnerability definitions and assessments using formalisation", International Journal of Climate Change Strategies and Management, Vol. 5 No. 1, pp. 54-70, doi: 10.1108/17568691311299363.

Zebisch, M. Schneiderbauer, S. Renner, K. Below, T. Brossmann, M. Ederer, W. and Schwan, S. (2017), "Risk supplement to the vulnerability sourcebook. Guidance on how to apply the vulnerability sourcebook's approach with the new IPCC AR5 concept of climate risk. Bonn", available at: www.adaptationcommunity.net/wp-content/uploads/2017/10/GIZ2017_Risk-Supplement-to-the-Vulnerability-Sourcebook.pdf

\section{Author affiliations}

Marc Zebisch, Institute for Earth Observation, Eurac Research, Bozen-Bolzano, Italy 
IJCCSM 13,1
Stefan Schneiderbauer, Institute for Earth Observation, Eurac Research, Bozen-Bolzano, Italy; United Nations University, United Nations University Institute for Environment and Human Security, Bonn, Germany and Geography, University of the Free State, Bloemfontein, South Africa

Kerstin Fritzsche, Institute for Future Studies and Technology Development (IZT), Berlin, GermanyPhilip Bubeck, University of Potsdam, Potsdam, GermanyStefan Kienberger, Interfaculty Department of Geoinformatics - Z_GIS, University of Salzburg, Salzburg, AustriaWalter Kahlenborn, Adelphi Consult GmbH, Berlin, GermanySusanne Schwan, and Till Below, Deutsche Gesellschaft für Internationale Zusammenarbeit (GIZ) GmbH, Cairo, Egypt

\section{About the authors}

Marc Zebisch is the head of the Institute for Earth Observation at Eurac Research in Bolzano, Italy (www.eurac.edu). He is specialised in climate impact and climate risk research. At Eurac Research he was involved in more than 20 international projects on environmental monitoring and climate change research including $8 \mathrm{FP} / \mathrm{H} 2020$ Projects. Furthermore, he works in international consultancy project on climate change risks for UNEP; the European Environment Agency (EEA), GIZ, The German (UBA-DE) and the Austrian (EAA) Environment Agency. He is member of the Alpine Climate Board of the Alpine Convention and the GEO initiative on mountains (Geo-Gnome). Marc Zebisch graduated at the Potsdam University (Institute for Geoecology) and obtained his Ph.D. at the Technical University of Berlin (Institute for Landscape Development) in 2004. From 2000 - 2005 he was working at the Potsdam Institute for Climate Impact Research (PIK) where he wrote his $\mathrm{PhD}$ on modelling the consequences of land-use changes on biodiversity. Marc Zebisch is the corresponding author and can be contacted at: marc.zebisch@eurac.edu

Stefan Schneiderbauer is Co-Head of the Global Mountain Safeguard Research (GLOMOS) Programme, a joint endeavour of UNU-EHS and Eurac Research in South Tyrol. His educational background is embedded in geoscience and the application of remote sensing techniques for natural resource management. He studied Geography at the University of Cologne (Germany) as well as at the Universite Louvain-La-Neuve (Belgium) and obtained his $\mathrm{PhD}$ from the Department for Geosciences of the Free University Berlin (Germany) with a dissertation on populations' risks and vulnerabilities to natural hazards. His main fields of research comprise of climate-related risk analyses, dynamic exposure assessments, social vulnerabilities and community resilience particularly within social-ecological systems in mountain regions.

Kerstin Fritzsche is currently leading the research area "Digitalisation" at the Institute for Futures Studies and Technology Assessments (IZT) in Berlin. Her research focuses on the opportunities and challenges of digitalisation for socio-ecological transformations and deals with the governance of digital development in the Global South against the backdrop of global challenges such as climate change. Before joining the IZT Kerstin Fritzsche worked as a senior researcher at the Institute for Advanced Sustainability Studies (IASS) in the research group "Digitalisation and Sustainability". Kerstin Fritzsche studied political science, Arabic studies and journalism at the University of Leipzig and the Stockholm University.

Philip Bubeck works as a Senior Researcher and Lecturer at the Department of Environmental Science and Geography of Potsdam University with a focus on climate change adaptation, vulnerability and disaster risk reduction. He is specialised in the development of approaches and methods for climate impact assessments, the design of empirical surveys, and the identification of suitable adaptation strategies at various societal levels.

Stefan Kienberger is a Senior Scientist and Project Manager at the Department of Geoinformatics Z_GIS at the Paris-Lodron University of Salzburg in Austria, where he leads the 'Integrated Spatial Indicators' research group. He holds a $\mathrm{PhD}$ in Geography from the University of Salzburg and an MSc in Environmental System Sciences - Geography from the University of Graz. Stefan is an expert in geospatial analysis, especially in developing integrated spatial indicators to represent complex and multi-dimensional phenomena. Much of his work is carried out in the context of climate change (adaptation), disaster risk reduction and the wider humanitarian context. Applied research work he carries out in a range of African, Asian, Latin American and European countries.

Walter Kahlenborn is co-founder and Managing Director of Adelphi research. The core topics of his research include vulnerability to climate change, climate change risk assessments and sustainable 
economic development. He advises German ministries, the European Commission, companies and international organisations. He has managed more than 100 national and international research and advisory projects concerning climate adaptation and mitigation, green economy and sustainable financial services. Walter Kahlenborn studied industrial engineering (Dipl.-Ing.) and history and philosophy (M.A.) in Berlin, Bologna and New Orleans

Till Below is an agricultural economist by training and works for the Deutsche Gesellschaft für Internationale Zusammenarbeit (GIZ) as a climate change adaptation expert. Currently, he works in a project of the German-Zambian development cooperation to support the development of climate risk insurance and climate risk information services for farmers. Previously he mainly worked on projects sourcebook and climate impact related to climate risk management, climate risk assessment and national adaptation planning. For his $\mathrm{PhD}$, he studied how farmers in Tanzania adapt to climate change.

For instructions on how to order reprints of this article, please visit our website: www.emeraldgrouppublishing.com/licensing/reprints.htm Or contact us for further details: permissions@emeraldinsight.com 